\title{
Maternal modifiers of the infant gut microbiota: metabolic consequences
}

\author{
Christopher M Mulligan and Jacob E Friedman \\ Section of Neonatology, Department of Pediatrics, University of Colorado Anschutz Medical Campus, Aurora, \\ Colorado, USA
}

Correspondence should be addressed to J E Friedman Email

jed.friedman@ucdenver.edu

\begin{abstract}
Transmission of metabolic diseases from mother to child is multifactorial and includes genetic, epigenetic and environmental influences. Evidence in rodents, humans and non-human primates support the scientific premise that exposure to maternal obesity or high-fat diet during pregnancy creates a long-lasting metabolic signature on the infant innate immune system and the juvenile microbiota, which predisposes the offspring to obesity and metabolic diseases. In neonates, gastrointestinal microbes introduced through the mother are noted for their ability to serve as direct inducers/ regulators of the infant immune system. Neonates have a limited capacity to initiate an immune response. Thus, disruption of microbial colonization during the early neonatal period results in disrupted postnatal immune responses that highlight the neonatal period as a critical developmental window. Although the mechanisms are poorly understood, increasing evidence suggests that maternal obesity or poor diet influences the development and modulation of the infant liver and other end organs through direct communication via the portal system, metabolite production, alterations in gut barrier integrity and the hematopoietic immune cell axis. This review will focus on how maternal obesity and dietary intake influence the composition of the infant gut microbiota and how an imbalance or maladaptation in the microbiota, including changes in early pioneering microbes, might contribute to the programming of offspring metabolism with special emphasis on mechanisms that promote chronic inflammation in the liver. Comprehension of these pathways and mechanisms will elucidate our understanding of developmental programming and may expand the avenue of opportunities for novel therapeutics.
\end{abstract}

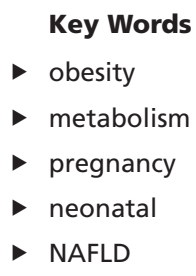

Journal of Endocrinology (2017) 235, R1-R12

\section{Introduction}

Nearly two-thirds of American women of childbearing age are overweight or obese and greater than half these women, once pregnant, have excess gestational weight gain (GWG) (Deputy et al. 2015, Nicklas \& Barbour 2015). Alterations in maternal microbiota composition, associated with both diet and obesity status, have been widely reported (Collado et al. 2008, 2012, Santacruz et al. 2010, Paul et al. 2016). Disruption of the mother's gut microbiota can influence early pioneering bacteria in the newborn and may be a prime candidate for intergenerational transmission of metabolic disease risk given the considerable influence these microbes have on gut function and immune system development. The newborn gut begins as an aerobic environment, allowing only certain microbes to temporarily take up residence, followed by dramatic fluctuations in microbe composition

This article is adapted from work presented at the Aspen/Snowmass Perinatal Biology Symposium, 27-30 August 2016. The meeting was supported in part by the Journal of Endocringlogntoaded from Bioscientifica.com at 04/26/2023 09:33:06AM 
with introduction of breast milk and solid foods (Voreades et al. 2014). Recent studies have proposed that colonization of the gastrointestinal tract begins in utero (Jimenez et al. 2008, Aagaard et al. 2014, Collado et al. 2016); however, this idea remains controversial, as discussed in detail by Perez-Muñoz et al. (2017). Regardless, the first major seeding of the gut microbiota is thought to occur during the birthing process following exposure to bacteria residing in the mother's vaginal canal and gut during vaginal birth or the mother's skin during a cesarean section (Dominguez-Bello et al. 2010). The mother's influence on neonatal acquisition of gut microbes continues by direct contact with the mother's skin and through breastfeeding, which provides critical nutrients to the colonizing bacteria and is a source of new bacteria. The diversity and density of bacteria continue to expand in response to new environmental exposures throughout the first few years of life until reaching a stable adult-like microbiota.

Several essential functions for human health develop in parallel with gut microbe expansion, including vitamin biosynthesis, energy extraction from the diet, gut barrier function and immune system maturation/education. The immune system of neonates is immature and requires the exposure of gut bacteria to develop properly. Depending on the health of the mother, maternal microbe communities may already be imbalanced when passed on to the infant. In children, metabolic diseases, including obesity, insulin resistance and nonalcoholic fatty liver disease (NAFLD), along with other related immune-based diseases, are associated with alterations in infant gut microbe composition (Fig. 1); however, the mechanisms remain unclear. This review will focus on maternal obesity, excessive GWG and high-fat diet consumption during pregnancy and their impact on the microbiota of both mother and infant, including their links to early gut colonization and innate immunity in the infants that drive an increased risk for common metabolic diseases.

\section{Development of the infant microbiota and immune tolerance}

The gut is the most densely populated of all the sites of microbial colonization, containing over 10 trillion bacteria cells, represented by more than 1000 different bacterial species. Mammals have evolved a mutual relationship with gut microbes, commonly referred to
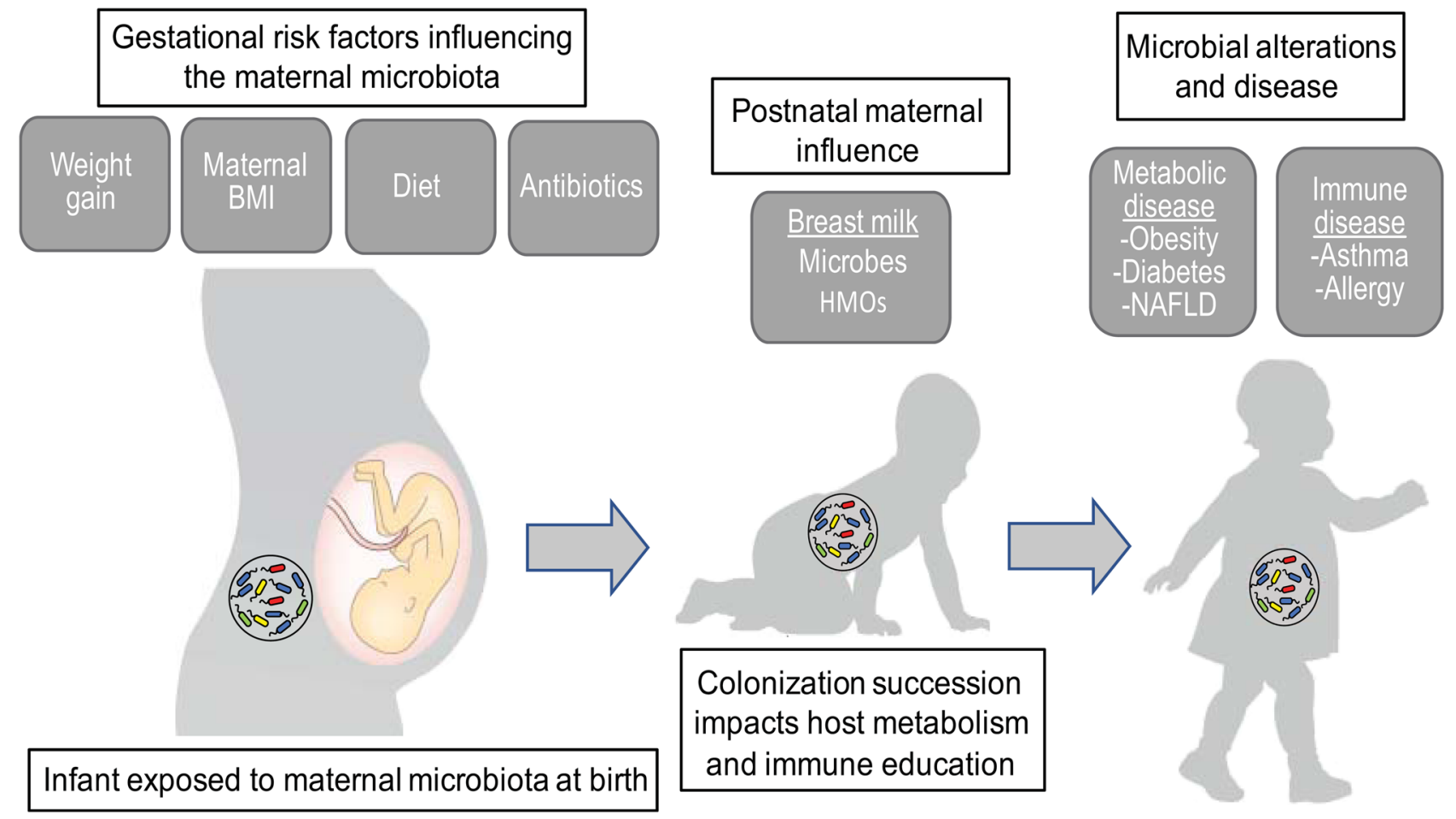

Figure 1

Influential factors on the maternal and infant microbiota. Maternal factors significantly contribute to the initial colonization and succession of the infant gut microbiota. Alterations in this process may have long-term health consequences related to host metabolism and immune education. HMOs, human milk oligosaccharides; NAFLD, nonalcoholic fatty liver disease.

http://joe.endocrinology-journals.org DOI: 10.1530/JOE-17-0303
๑) 2017 Society for Endocrinology Printed in Great Britain
Published by Bioscientifica Ltd 
as 'commensal'. Colonization of the infant gut by these commensals during the first few years of life is a time of significant fluctuation and maturation. Early alterations in the normal succession of the gut microbiota may have an impact on future colonization (Eggesbø et al. 2011), which could have lasting health consequences.

Commensal colonization progresses through a choreographed succession of bacterial species and evolves rapidly during the first months of life (Del Chierico et al. 2015, Hill et al. 2017). Systemic responses to commensal microbiota are essential for the maintenance of beneficial host-microbiota interactions. For example, maternally acquired IgA and IgG in neonatal mice leads to dampened $\mathrm{T}$ cell-dependent immune responses against commensal bacteria (Koch et al. 2016). Additionally, systemic IgG responses to gram-negative bacteria, acquired early and over the course of life, were shown to provide crossprotection against gram-negative pathogens, such as Escherichia coli and Salmonella, in mice (Zeng et al. 2016). These observations reinforce the concept that microbial composition and the timing of host-commensal interactions provide the foundation for balanced immunity in the intestine.

Under healthy conditions, vaginally delivered infants born to normal-weight mothers are initially colonized by mostly facultative anaerobic bacteria including Staphylococcus, Streptococcus, E. coli and Enterobacteria. These anaerobes make the habitat suitable for colonization by strict anaerobes including Bacteroides, Bifidobacterium and Clostridium (Penders et al. 2006, Palmer et al. 2007), by consuming oxygen, altering the $\mathrm{pH}$, lowering the redox potential and producing carbon dioxide and nutrients. Jakobsson and coworkers (Jakobsson et al. 2014) reported a similar succession of colonization, including an initial blooming of Proteobacteria that gradually declined from 1 week to 24 months, Firmicutes that expanded from 3 months onward and a peak of Actinobacteria at 3 months. This pattern of colonization was similar in infants born by cesarean section, except the notably higher proportion of Bacteroidetes in vaginally-delivered infants during the first 12 months of life. E. coli is a member of the Proteobacteria phylum and is the most abundant facultative anaerobe in the mammalian gut microbiota, but under homeostatic conditions, this species represents only a minor fraction of the ecosystem. Nevertheless, Proteobacteria abundance may explain significant functional variability in the human gut microbiome (Bradley \& Pollard 2017). Importantly, E. coli (like many other members of the family Enterobacteriaceae) has a short doubling time and a highly flexible metabolic capacity. These attributes make this bacterium highly adaptable and allows it to bloom in the presence of oxygen and nitrogen.

\section{The importance of Proteobacteria to immune education in early life}

An emerging paradigm, originally known as 'The Restaurant Hypothesis' (Leatham-Jensen et al. 2012), posits that nutritional stress may alter the original colonizing bacteria, including E. coli; therefore, the signaling pathways controlled by microbial mediators may cause fine-tuning in the gut, potentially altering the immune system in early life. Several studies suggest that the critical immune mechanisms controlling the maintenance of homeostasis and tolerance to environmental exposures are determined by microbialhost interactions occurring during a narrow time frame contained within the earliest days of life (Koch et al. 2016, Zeng et al. 2016). The early colonization of Proteobacteria and its subsequent reduction in abundance over time is thought to be an important part of this process, whereby a disruption of this progression has been linked to an increased risk of neonatal diseases, particularly in preterm infants (Neu 2015, 2016). The Proteobacteria bloom in the neonatal gut is likely under maternal control. Human milk oligosaccharides (HMOs) (De Leoz et al. 2015) and secretory IgA production (Mirpuri et al. 2014) are involved in the selective suppression of Proteobacteria during establishment of the early gut flora.

Proteobacteria are believed to be important contributors to inflammation associated with metabolic disease in adults, but their role in infant immunity is critical for early priming of the innate and adaptive immune system. A primary structural component of gram-negative bacteria residing in the gut is the endotoxin lipopolysaccharide (LPS). Translocation of LPS from the gut into the systemic circulation has been widely reported in metabolic disease (Cani et al. 2007, Ruiz et al. 2007, Lassenius et al. 2011). A common theme that has recently emerged is that variability in the lipid A component of LPS can tip the balance of innate immune responses toward homeostatic tolerance or pro-inflammatory signaling, affecting adaptive immune responses that either alter or inhibit protective signaling normally induced by toll-like receptors (TLRs). Lipid A, the biologically active moiety of LPS, can be expressed in variant forms by many human pathogens, allowing for evasion of the host innate immune system and establishment of a chronic infection. Strikingly, several of these host-adapted gram-negative

Published by Bioscientifica Ltd. 
bacteria that express immune-evasive lipid A are associated with increased risk of autoimmune disease (Vatanen et al. 2016), type I diabetes, atherosclerosis (Erridge et al. 2007b, Slocum et al. 2014) and allergic disorders in childhood and adulthood (Grönlund et al. 2000, Ogra \& Welliver 2008). A role of lipid A variants is to allow a bacterium to evade TLR4 and promote chronic inflammation, and these variants appear to act through dysregulation of both innate and adaptive immune responses (Kramer \& Genco 2017).

While a close relationship exists between microbial flora and the intestinal epithelium, the mechanisms whereby the mucosal surface senses the presence of colonizing microbial organisms and allows for innate immune receptor-mediated responses is largely unknown (Hooper et al. 1999). Recognition of microbial structures by mammalian cells occurs through various transmembrane receptor molecules that are part of the innate immune system. TLRs recognize conserved microbial structures, such as LPS, mediate cellular activation, and thereby provide the costimulatory signal required for an efficient immune response (Medzhitov 2001). Initial exposure to bacteria and LPS in early infancy has been shown to contribute to the development of the immune system by educating it to appropriately respond to bacteria and their components. Different bacterial species have variations in their LPS structure that impact their ability to elicit an innate immune response (Whitfield \& Trent 2014, Vatanen et al. 2016).

The immunological phenomenon wherein prior exposure to TLR ligands renders macrophages refractory to LPS-elicited pro-inflammatory cytokine secretion is known as endotoxin tolerance (Biswas et al. 2007). Endotoxin tolerance is classically induced by exposure to low levels of LPS, thereby rendering the cells 'tolerant' to subsequent endotoxin challenge, characterized functionally by a marked inhibition of inflammatory cytokine (e.g. TNF- $\alpha$, IL-1, and IL-6) production upon re-challenge with endotoxin (Erroi et al. 1993, Granowitz et al. 1993). This immune-regulatory process of induction is also associated with a unique metabolic phenotype in macrophages that facilitates persistent improvements in antimicrobial function (phagocytosis) against gram-negative bacteria (Coveney et al. 2015, Fensterheim et al. 2017). Immediately following TLR stimulation, macrophages shift their metabolic profile to one that favors glycolysis over oxidative metabolism (Everts et al. 2014) promoting a proinflammatory phenotype. In contrast, anti-inflammatory macrophages exhibit a metabolic program of augmented oxidative phosphorylation (Kelly \& O'Neill 2015). The lack of appropriate alterations in early immune education may affect the overall functionality of the microbiota and macrophages, thereby altering inflammation and key pathogens that can drive shifts in the community composition into dysbiosis later in life.

We have recently shown in a prospective study on vaginally delivered, exclusively breastfed infants with no neonatal or postnatal exposure to antibiotics that neonates born to mothers with obesity showed a significant 50\% reduction in Gammaproteobacteria at 2 weeks of age compared with infants of normal-weight mothers (Lemas et al. 2016). A striking relative depletion in Proteobacteria species was recently found in 2-day-old neonates delivered vaginally, but not by cesarean section, to overweight/obese mothers (Mueller et al. 2016), suggesting the differences in relative abundance of gramnegative bacteria may stem from vertical transmission of the maternal microbiota. It is also important to note that maternal overweight/obesity could be due to a mix of environmental as well as genetic factors not accounted for, such as excess GWG or poor diet, both of which likely has its own effect on microbial community structure. Based on studies in mice (Mirpuri et al. 2014), induction of a Gammaproteobacteria-specific IgA response partially regulated the transition from a neonatal to a mature microbiota. Experiments in germfree mice showed that colonization with microbes from mice lacking IgA had persistent increased colonization with Gammaproteobacteria that resulted in sustained intestinal inflammation and increased susceptibility to neonatal and adult models of intestinal injury. Thus, the effects of a relative depletion of intestinal Proteobacteria species in neonates of mothers with obesity could cause persistent alterations in immune development and increase an infant's risk of developing inflammatory and metabolic diseases, but the literature on this topic in fullterm human neonates is scarce.

One theory for why mothers with obesity have infants with reduced Proteobacteria and potentially more inflammation could be as simple as micronutrient deficiency. Although not universal, mothers with obesity and those with excess GWG are iron deficient (Dosch et al. 2016, Jones et al. 2016), as well as their infants. A wide range of host immune responses are intricately linked with both systemic and cellular iron homeostasis. Perturbations to the labile iron pool have been linked with modulating various forms of innate and adaptive immune functions including proliferation, differentiation and secretion of inflammatory mediators (Ellermann \& Arthur 2017). Processes associated with inflammation,

Published by Bioscientifica Ltd. 
including cytokine production and engagement of TLRs by microbial ligands, stimulate the production of the hormone hepcidin, which in turn modulates systemic iron homeostasis by limiting dietary iron absorption and increasing intracellular retention of iron (Nemeth et al. 2004a,b, Drakesmith \& Prentice 2012). Given that bacteria can secrete small molecules known as siderophores that can solubilize iron for host cells (Deriu et al. 2013), the opportunity is present for resident bacteria to modulate host immune responses at the mucosal interface. Iron has also been shown to modulate butyrate-producing bacteria (Tang et al. 2016), as well as pathogenic Proteobacteria (Kamada et al. 2013). Whether iron deficiency has a direct effect on early microbiota colonization and inflammation is a hypothesis worthy of further study.

\section{Maternal gestational weight status and dietary intake impacts the development of the infant microbiota}

The mother has a direct role in initially colonizing the infant microbiota as is evidenced by the fact that infants born vaginally have different microbiota compositions than infants born by cesarean sections (DominguezBello et al. 2010). While it is unclear whether these early differences in microbiota composition affect the subsequent commensal colonization into childhood and beyond, it is clear the mother's microbes do contribute to the colonization process. The gut microbiota has been shown to be altered with advancing gestation in normalweight mothers, and when these microbes were transferred into germ-free mice, the mice receiving microbes from mothers in the 3rd trimester showed increased weight gain, inflammation and insulin resistance (Koren et al. 2012). It should come as no surprise that obesity, weight gain and diet also alter the maternal microbiota composition during pregnancy, but whether this has a significant impact on metabolic disease risk is still under investigation.

To date, there are only a few studies that have explored the impact of maternal obesity and diet on maternal and infant microbiota, but the existing data suggest that there is a significant impact. Collado and coworkers (Collado et al. 2008) found that women that were obese prior to pregnancy had significantly different gut microbiota compositions compared with normal-weight pregnant women during both the 1st and 3rd trimesters of pregnancy. Furthermore, women that gained excessive gestational weight regardless of pre-pregnancy BMI had significant differences in their microbiota composition compared with women who had normal weight gain. Specifically, Bacteroides and Staphylococcus were significantly higher in obese women and Bacteroides species were elevated in all women with excessive GWG. Santacruz and coworkers (Santacruz et al. 2010) also found a difference in gut microbiota composition between normal-weight and overweight women. Overweight women were found to have significantly more Staphylococcus, Enterobacteriaceae and E. coli and fewer Bifidobacterium and Bacteroides compared with normalweight pregnant women. They also reported that women with excessive GWG had significantly more $E$. coli and fewer Bifidobacterium and Akkermansia muciniphila than in women with normal weight gain during pregnancy. Although there are some inconsistencies in the results of these studies, it is important to note that the samples were taken at different times during pregnancy and that one study compared normal-weight women to women with obesity and the other compared normal-weight and overweight women, which could account for the different findings. The important observation is that their microbiota is different from normal-weight pregnant women and that these differences (whether due to diet or body habitus) could influence the microbial colonization of the infant, as noted earlier. Collado and coworkers (Collado et al. 2010) compared the microbiota of infants at 1 and 6 months of age that were born to overweight mothers (based on pre-pregnancy BMI) vs mothers that were normal weight. Infants born to overweight mothers were found to have increased Bacteroides and Staphylococcus at 1 and 6 months of age. This observation coincides with what this group showed in mothers during pregnancy (Collado et al. 2008), providing evidence for the mother's role in directing the early infant microbiota composition. Maternal obesity has also been associated with long-term changes in the offspring microbiota. Galley and coworkers (Galley et al. 2014) found that toddlers born to mothers with obesity had significantly elevated levels of Oscillibacter, Parabacteroides and an unclassified Bacteroidales genus and reduced levels of Eubacterium and Blautia compared with toddlers born to normal-weight mothers; however, these studies did not control for mode of delivery, antibiotic use or breastfeeding exposure.

Maternal diet has also been shown to have a significant impact on the microbiota composition of the offspring. Recently, Chu and coworkers (Chu et al. 2016) showed that a maternal high-fat diet, estimated

Published by Bioscientifica Ltd. 
from retrospective surveys, resulted in a depletion of Bacteroides and an enrichment of Enterococcus in the meconium and a trend for reduction of Bacteroides at 6 weeks of age. Evidence of the impact on maternal diet has also been reported in animal models including both rodent and non-human primate models. In a study by Myles and coworkers (Myles et al. 2013), feeding pregnant mouse dams a Western-style diet resulted in an altered microbiota composition in the offspring including an increase in Clostridiales (a class of Firmicutes), despite being weaned onto a control diet. In addition to having an altered microbiota composition, these offspring also had worse outcomes in models of infection, autoimmunity and allergic sensitization. Importantly, in non-human primates, infants born to mothers fed a high-fat diet during gestation and lactation (whether obese or not) showed significant intestinal dysbiosis that was not completely corrected by switching to a control diet after weaning (Ma et al. 2014). This has important clinical relevance as the early colonized bacteria, driven by maternal diet, may have a long-lasting effect on the commensal microbe population in offspring, therefore, setting the stage for increased risk for immunologic and metabolic disease patterning.

\section{The important role of breast milk in colonization of the infant gut microbiota}

The impact of the mother's microbiota on the colonization of the infant gut continues after initial colonization at birth through breastfeeding. Breast milk is a source of live bacteria and contains energy sources for colonizing bacteria. Breast milk has also been shown to play a role in preventing the colonization of pathogenic bacteria (Jantscher-Krenn et al. 2012). Assessment of the bacterial composition of breast milk in healthy women has revealed the presence of a wide variety of bacteria, including Staphylococcus, Streptococcus, Lactobacillus, Bifidobacterium and E. coli (Heikkilä \& Saris 2003, Martín et al. 2007). Conversely, breast milk from mothers with obesity has been shown to harbor a different and less diverse bacterial community than that of normal-weight subjects, including higher levels of Staphylococcus and A. muciniphila and lower levels of Bifidobacterium (CabreraRubio et al. 2012, Collado et al. 2012), and a different composition of hormones, cytokines and oligosaccharides (Andreas et al. 2014). The source of bacteria in breast milk is unclear, but there is evidence suggesting bacteria residing in the gut might be a source of the breast milk populations (Latuga et al. 2014, Rodríguez 2014).
HMOs are an important component of breast milk and given the fact that they are indigestible to the human host, they are now believed to exist for the primary purpose of providing nutrients to the microbes colonizing the infant gut. There are over 200 known HMO molecules that are present in human breast milk, which vary across individuals (Ninonuevo et al. 2006). Recently, differences in HMO composition in mother's milk have been associated with infant growth and body composition (Alderete et al. 2015).

Breastfeeding compared to formula feeding is thought to provide significant health benefits to an infant, specifically reducing the risk of obesity (Dieterich et al. 2013, Binns et al. 2016), where the risk is inversely related to the duration (Ip et al. 2009). Given the microbial and HMO differences found in the breast milk of obese women compared with normal-weight women, this benefit may not be universal, but more research is needed to determine if the benefits outweigh the risks. Support for this concern is evidenced by the fact that antibiotic use in infants born to normal-weight mothers increases the risk of obesity, whereas antibiotic use in infants born to mothers with obesity reduces the risk of obesity (Ajslev et al. 2011). This indirectly suggests that it might be advantageous to alter the composition of the gut microbiota in infants born to mothers with obesity.

\section{Obesity and the programming of hematopoietic immune cells}

The microbiota has been implicated in altering immune system function via changes in hematopoiesis. Dietary changes can have major effects on microbial composition and release of LPS that provokes inflammation, insulin resistance and may even program bone marrow-derived stem cells (Giusti et al. 2017). The significant increase in common myeloid progenitor cells derived from the bone marrow in diet-induced obese mice is thought to be the result of an altered microbiota composition (Luo et al. 2015). Indeed, recent evidence has emerged to indicate that innate immune memory can be transferred via hematopoietic stem and progenitor cells that alter the function of their differentiated progeny (Ng et al. 2013), depending upon the composition of the microbiota (Burgess et al. 2014). Thevaranjan and coworkers (Thevaranjan et al. 2017) showed that old mice had a distinct microbiota composition compared with young mice. Bone marrow-derived macrophages and whole blood from germ-free mice colonized with

Published by Bioscientifica Ltd. 
gut microbiota from the old mice produced increased levels of inflammatory cytokines following stimulation by LPS compared with young mice. Singer and coworkers (Singer et al. 2014) found that high-fat diet increases the production of bone marrow-derived dendritic cells and peritoneal macrophages from obese mice, and they produce more inflammatory cytokines including TNF- $\alpha$ and IL-6 following LPS stimulation than lean mice; their findings suggest that this pro-inflammatory profile persists after the obesogenic diet is removed.

\section{Commensal bacteria at the crossroad between inflammation and childhood NAFLD}

Maternal obesity and diabetes are among the most powerful predictors of childhood obesity and other adverse health outcomes such as NAFLD, that affects up to $34 \%$ of obese children (Anderson et al. 2015). A particularly alarming statistic is the prevalence of obesity in children, affecting $10 \%$ of infants and toddlers and $17 \%$ of children and adolescents in the United States (Ogden et al. 2012). With the rise of obesity, it is predicted that NAFLD will be the most common etiology for liver transplantation in the 21st century (Agopian et al. 2012). A cross-sectional study of 538 children with biopsy-proven NAFLD illustrated the critical importance of the in utero environment to the development of pediatric NAFLD (Newton et al. 2017). They showed that children born with high or low birth weight had $>2$-fold significantly increased incidence of nonalcoholic steatohepatitis (NASH) or advanced fibrosis, respectively, compared with those of normal birth weight.

Evidence suggests that the transgenerational passage of the maternal obese phenotype with NAFLD, or developmental programming of the offspring, involves the innate immune system as well as metabolic perturbations by gut microbes (Wesolowski et al. 2017). Because early immune development is highly dependent on triggers provided by the microbiota (Ma et al. 2014), infants born to obese mothers are exposed to products of gut dysbiosis that activate macrophages in the gut and bone marrow. However, the timing, mechanisms involved and whether interventions that alter microbial colonization can prevent early innate immune system 'programming' are unknown. Results from recent studies demonstrate that the maternal microbiota impels early postnatal innate immune development (Gomez de Agüero et al. 2016). In adults, the transmissibility of obesity and related disorders by gut bacteria is likely mediated specifically by cells of the innate immune system, a phenomenon that is observed in Rag1 mice lacking all cells of the adaptive immune system (Bäckhed et al. 2004).

The source of inflammation in macrophages associated with NAFLD is incompletely understood; however, increased circulating levels of the bacterialderived endotoxin LPS is believed to play a role. Alterations in microbial composition have been associated with increased gut permeability, resulting in translocation of LPS. Binding of LPS to TLRs triggers the release of cytokines and an associated inflammatory response. LPS will bind to LPS-binding protein (LBP) and that complex will bind to CD14, located in inflammatory cells. Together LPS-LBP-CD14 activates TLR4, which is present in hepatocytes, adipocytes, Kupffer cells, the most abundant macrophage in the body and hepatic stellate cells, triggering the release of inflammatory cytokines (i.e. TNF- $\alpha$, IL-1 $\beta$ and IL-6). Furthermore, the translocation of LPS from the gut is not reserved to individuals with disease. Studies have shown the ingestion of meals containing fat increase systemic LPS concentrations in healthy individuals (Erridge et al. 2007a, Ghanim et al. 2009, 2010, Laugerette et al. 2011). Under normal circumstances, once the toxin is neutralized and removed, the state of inflammation returns to baseline levels. If endotoxin exposure becomes chronic, a low-grade inflammatory state may be maintained, contributing to tissue damage and acceleration of metabolic diseases. Those microbes most successful at driving inflammatory disease processes have evolved to interfere with host gene expression and metabolism. Many of these pathogens persist inside the cells of the immune system. Miskinyte and Gordo (Miskinyte \& Gordo 2013) examined how a commensal E. coli was able to develop the virulence needed to persist inside macrophages of the immune system. Working in mice, they found that when maintained in vitro under the selective pressure of host macrophages, commensal E. coli can evolve virulent clones that escape phagocytosis and macrophage killing in vitro, while increasing their pathogenicity in vivo.

A study by Cani and coworkers (Cani et al. 2007) showed that an infusion of LPS for 4 weeks in mice led to increased weight gain and development of insulin resistance, similar to mice fed a high-fat diet, providing a causative role for gut microbiota in the development of metabolic disease. In our non-human primate model of maternal obesity, high-fat diet exposure increased fetal hepatic oxidative stress and apoptosis in the early 3 trimester, perhaps priming the liver for later development of NASH (McCurdy et al. 2009). Furthermore, there is

Published by Bioscientifica Ltd. 
innate immune dysfunction and necro-inflammatory changes in juvenile offspring of high-fat diet-fed dams (Thorn et al. 2014). Importantly, these alterations persist even after weaning to a normal chow diet. Lastly, in this model, a maternal high-fat diet, regardless of maternal weight gain, leads to persistent gut dysbiosis in juvenile offspring switched to a healthy diet at weaning (Ma et al. 2014).

Emerging evidence suggests that the severity of NAFLD postnatally is strongly associated with gut dysbiosis (Boursier et al. 2016) and a shift in gut metabolic function, including production and utilization of short-chain fatty acids and bile acids. Given the early gut permeability engendered by a dysbiotic infant microbe community, it is tempting to speculate that certain bacteria and their outputs might trigger programming events in the liver, and in progenitor cells in the bone marrow as well (see discussion earlier). We recently found that pregnant mice fed a Westernstyle diet produced an early programming effect on the gut microbiota and on bone marrow-derived macrophage polarization in 3-week-old offspring, suggesting that shaping of the early gut microbiota and programming of macrophages during the early weaning period are crucial for the development of NAFLD and fibrosis in adulthood (K R Jonscher \& J E Friedman, unpublished observations). The early microbes and the microenvironment and mechanisms responsible for programming myeloid cells within the bone marrow and liver of obese offspring warrant further research.

\section{Problems and future challenges in determining causation in early microbiota colonization}

Early alterations in the infant microbiota composition are associated with the development of both metabolic and immune diseases, but causation in humans is lacking. Models imploring the use of germ-free animals or antibiotics have been the primary methods for isolating and studying the impact of the microbiota on human health. Studies using germ-free animals have produced compelling evidence for the role of the microbiota in obesity development and education of the immune system (Turnbaugh et al. 2006, Ridaura et al. 2013, Weng \& Walker 2013), improving our understanding of the contribution of the microbiota in disease progression. Unfortunately, these studies do not provide sufficient information about the role of the microbiota in the initiation of the disease, or whether an altered microbiota is a cause or just a consequence of disease. Another challenge is that there is still significant controversy over what is considered a healthy or diseased microbiota. This controversy is highlighted in a recent review (Sze \& Schloss 2016) evaluating studies that reported the microbiota in subjects with obesity, which suggests that we are still unable to conclusively define the composition of an obese microbiota. One reason it has been difficult to assign health benefits to a specific microbiota composition is because of the functional redundancy found across various bacterial groups (Moya \& Ferrer 2016). Future studies are needed to explore the impact of individual bacterial species, their interactions with each other and with their host, and how they contribute to disease development.

Long-term studies are needed to determine if an altered microbiota composition alone is sufficient for disease development or whether a secondary stressor like diet is needed to accelerate disease. Identifying a programming effect due to early 'obese microbes' that fine tunes the infant gut may require a second hit to reveal the causes for developmental programming of the immune and metabolic systems in early life. This has been done on a limited basis in studies showing that microbial composition dictates susceptibility to disease development in humans (Spencer et al. 2011) and animals (Le Roy et al. 2013) providing support for a causal relationship, but only in response to a secondary insult (i.e. diet). Ongoing studies are currently exploring the interaction between the microbiota composition and diet to better understand the impact of this interaction in disease development. Additionally, determining whether there are legacy costs of early alterations in microbial succession that are maintained long after the microbiota has adapted to solid foods and reached maturity and stability are also important to understand the full impact of an early alteration in the infant microbiota composition. As we continue to learn more about the importance of early bacterial colonization, we can develop strategies for interventions that could reduce the future incidence of a wide variety of metabolic and immune diseases.

Declaration of interest

The authors declare that there is no conflict of interest that could be perceived as prejudicing the impartiality of this review.

\section{Funding}

This work was supported by the NIH Colorado Nutrition and Obesity Research Center (NORC) grant P30 DK048520 (CMM, JEF).

Published by Bioscientifica Ltd. 


\section{Acknowledgements}

This work was supported in part by NIH R24-DK102766-06 and NIH-R01DK140443 to JF. The authors thank Rachel Janssen for her expert assistance editing the manuscript.

\section{References}

Aagaard K, Ma J, Antony KM, Ganu R, Petrosino J \& Versalovic J 2014 The placenta harbors a unique microbiome. Science Translational Medicine $6237 \mathrm{ra} 265$.

Agopian VG, Kaldas FM, Hong JC, Whittaker M, Holt C, Rana A, Zarrinpar A, Petrowsky H, Farmer D, Yersiz H, et al. 2012 Liver transplantation for nonalcoholic steatohepatitis: the new epidemic. Annals of Surgery 256 624-633. (doi:10.1097/SLA.0b013e31826b4b7e)

Ajslev TA, Andersen CS, Gamborg M, Sorensen TI \& Jess T 2011 Childhood overweight after establishment of the gut microbiota: the role of delivery mode, pre-pregnancy weight and early administration of antibiotics. International Journal of Obesity 35 522-529. (doi:10.1038/ijo.2011.27)

Alderete TL, Autran C, Brekke BE, Knight R, Bode L, Goran MI \& Fields DA 2015 Associations between human milk oligosaccharides and infant body composition in the first 6 mo of life. American Journal of Clinical Nutrition 102 1381-1388. (doi:10.3945/ajcn.115.115451)

Anderson EL, Howe LD, Jones HE, Higgins JP, Lawlor DA \& Fraser A 2015 The prevalence of non-alcoholic fatty liver disease in children and adolescents: a systematic review and meta-analysis. PLOS ONE $\mathbf{1 0}$ e0140908. (doi:10.1371/journal.pone.0140908)

Andreas NJ, Hyde MJ, Gale C, Parkinson JR, Jeffries S, Holmes E \& Modi N 2014 Effect of maternal body mass index on hormones in breast milk: a systematic review. PLOS ONE 9 e115043. (doi:10.1371/journal. pone.0115043)

Bäckhed F, Ding H, Wang T, Hooper LV, Koh GY, Nagy A, Semenkovich CF \& Gordon JI 2004 The gut microbiota as an environmental factor that regulates fat storage. PNAS 101 15718-15723. (doi:10.1073/ pnas.0407076101

Binns C, Lee M \& Low WY 2016 The long-term public health benefits of breastfeeding. Asia-Pacific Journal of Public Health 28 7-14. (doi:10.1177/1010539515624964)

Biswas SK, Bist P, Dhillon MK, Kajiji T, Del Fresno C, Yamamoto M, LopezCollazo E, Akira S \& Tergaonkar V 2007 Role for MyD88-independent, TRIF pathway in lipid A/TLR4-induced endotoxin tolerance. Journal of Immunology 179 4083-4092. (doi:10.4049/jimmunol.179.6.4083)

Boursier J, Mueller O, Barret M, Machado M, Fizanne L, Araujo-Perez F, Guy CD, Seed PC, Rawls JF, David LA, et al. 2016 The severity of nonalcoholic fatty liver disease is associated with gut dysbiosis and shift in the metabolic function of the gut microbiota. Hepatology $\mathbf{6 3}$ 764-775. (doi:10.1002/hep.28356)

Bradley PH \& Pollard KS 2017 Proteobacteria explain significant functional variability in the human gut microbiome. Microbiome 536. (doi:10.1186/s40168-017-0244-z)

Burgess SL, Buonomo E, Carey M, Cowardin C, Naylor C, Noor Z, Wills-Karp M \& Petri WA Jr 2014 Bone marrow dendritic cells from mice with an altered microbiota provide interleukin 17A-dependent protection against Entamoeba histolytica colitis. mBio 5 e01817. (doi:10.1128/mBio.02046-14)

Cabrera-Rubio R, Collado MC, Laitinen K, Salminen S, Isolauri E \& Mira A 2012 The human milk microbiome changes over lactation and is shaped by maternal weight and mode of delivery. American Journal of Clinical Nutrition 96 544-551. (doi:10.3945/ajcn.112.037382)

Cani PD, Amar J, Iglesias MA, Poggi M, Knauf C, Bastelica D, Neyrinck AM, Fava F, Tuohy KM, Chabo C, et al. 2007 Metabolic endotoxemia initiates obesity and insulin resistance. Diabetes 56 1761-1772. (doi:10.2337/db06-1491)
Chu DM, Antony KM, Ma J, Prince AL, Showalter L, Moller M \& Aagaard KM 2016 The early infant gut microbiome varies in association with a maternal high-fat diet. Genome Medicine 8 77. (doi:10.1186/s13073016-0330-z)

Collado MC, Isolauri E, Laitinen K \& Salminen S 2008 Distinct composition of gut microbiota during pregnancy in overweight and normal-weight women. American Journal of Clinical Nutrition $\mathbf{8 8}$ 894-899.

Collado MC, Isolauri E, Laitinen K \& Salminen S 2010 Effect of mother's weight on infant's microbiota acquisition, composition, and activity during early infancy: a prospective follow-up study initiated in early pregnancy. American Journal of Clinical Nutrition 92 1023-1030. (doi:10.3945/ajcn.2010.29877)

Collado MC, Laitinen K, Salminen S \& Isolauri E 2012 Maternal weight and excessive weight gain during pregnancy modify the immunomodulatory potential of breast milk. Pediatric Research $\mathbf{7 2}$ 77-85. (doi:10.1038/pr.2012.42)

Collado MC, Rautava S, Aakko J, Isolauri E \& Salminen S 2016 Human gut colonisation may be initiated in utero by distinct microbial communities in the placenta and amniotic fluid. Scientific Reports 6 23129. (doi:10.1038/srep23129)

Coveney AP, Wang W, Kelly J, Liu JH, Blankson S, Wu QD, Redmond HP \& Wang JH 2015 Myeloid-related protein 8 induces self-tolerance and cross-tolerance to bacterial infection via TLR4- and TLR2-mediated signal pathways. Scientific Reports 5 13694. (doi:10.1038/srep13694)

De Leoz ML, Kalanetra KM, Bokulich NA, Strum JS, Underwood MA, German JB, Mills DA \& Lebrilla CB 2015 Human milk glycomics and gut microbial genomics in infant feces show a correlation between human milk oligosaccharides and gut microbiota: a proof-ofconcept study. Journal of Proteome Research 14 491-502. (doi:10.1021/ pr500759e)

Del Chierico F, Vernocchi P, Petrucca A, Paci P, Fuentes S, Praticò G, Capuani G, Masotti A, Reddel S, Russo A, et al. 2015 Phylogenetic and metabolic tracking of gut microbiota during perinatal development. PLoS ONE 10 e0137347. (doi:10.1371/journal.pone.0137347)

Deputy NP, Sharma AJ, Kim SY \& Hinkle SN 2015 Prevalence and characteristics associated with gestational weight gain adequacy. Obstetrics and Gynecology 125 773-781. (doi:10.1097/ AOG.0000000000000739)

Deriu E, Liu JZ, Pezeshki M, Edwards RA, Ochoa RJ, Contreras H, Libby SJ, Fang FC \& Raffatellu M 2013 Probiotic bacteria reduce salmonella typhimurium intestinal colonization by competing for iron. Cell Host and Microbe 14 26-37. (doi:10.1016/j.chom.2013.06.007)

Dieterich CM, Felice JP, O'Sullivan E \& Rasmussen KM 2013 Breastfeeding and health outcomes for the mother-infant dyad. Pediatric Clinics of North America 60 31-48. (doi:10.1016/j.pcl.2012.09.010)

Dominguez-Bello MG, Costello EK, Contreras M, Magris M, Hidalgo G, Fierer N \& Knight R 2010 Delivery mode shapes the acquisition and structure of the initial microbiota across multiple body habitats in newborns. PNAS 107 11971-11975. (doi:10.1073/pnas.1002601107)

Dosch NC, Guslits EF, Weber MB, Murray SE, Ha B, Coe CL, Auger AP \& Kling PJ 2016 Maternal obesity affects inflammatory and iron indices in umbilical cord blood. Journal of Pediatrics 172 20-28. (doi:10.1016/j.jpeds.2016.02.023)

Drakesmith H \& Prentice AM 2012 Hepcidin and the iron-infection axis Science 338 768-772. (doi:10.1126/science.1224577)

Eggesbø M, Moen B, Peddada S, Baird D, Rugtveit J, Midtvedt T, Bushel PR, Sekelja M \& Rudi K 2011 Development of gut microbiota in infants not exposed to medical interventions. APMIS 119 17-35. (doi:10.1111/j.1600-0463.2010.02688.x)

Ellermann M \& Arthur JC 2017 Siderophore-mediated iron acquisition and modulation of host-bacterial interactions. Free Radical Biology and Medicine 105 68-78. (doi:10.1016/j.freeradbiomed.2016.10.489)

Erridge C, Attina T, Spickett CM \& Webb DJ 2007a A high-fat meal induces low-grade endotoxemia: evidence of a novel mechanism of http://joe.endocrinology-journals.org

DOI: $10.1530 / J O E-17-0303$
๑) 2017 Society for Endocrinology Printed in Great Britain
Published by Bioscientifica Ltd 
postprandial inflammation. American Journal of Clinical Nutrition $\mathbf{8 6}$ 1286-1292.

Erridge C, Spickett CM \& Webb DJ $2007 b$ Non-enterobacterial endotoxins stimulate human coronary artery but not venous endothelial cell activation via Toll-like receptor 2. Cardiovascular Research 73 181-189. (doi:10.1016/j.cardiores.2006.11.004)

Erroi A, Fantuzzi G, Mengozzi M, Sironi M, Orencole SF, Clark BD, Dinarello CA, Isetta A, Gnocchi P \& Giovarelli M 1993 Differential regulation of cytokine production in lipopolysaccharide tolerance in mice. Infection and Immunity 61 4356-4359.

Everts B, Amiel E, Huang SC, Smith AM, Chang CH, Lam WY, Redmann V, Freitas TC, Blagih J, van der Windt GJ, et al. 2014 TLR-driven early glycolytic reprogramming via the kinases TBK1-IKKe supports the anabolic demands of dendritic cell activation. Nature Immunology $\mathbf{1 5}$ 323-332. (doi:10.1038/ni.2833)

Fensterheim BA, Guo Y, Sherwood ER \& Bohannon JK 2017 The cytokine response to lipopolysaccharide does not predict the host response to infection. Journal of Immunology 198 3264-3273. (doi:10.4049/ jimmunol.1602106)

Galley JD, Bailey M, Kamp Dush C, Schoppe-Sullivan S \& Christian LM 2014 Maternal obesity is associated with alterations in the gut microbiome in toddlers. PLOS ONE 9 e113026. (doi:10.1371/journal. pone.0113026)

Ghanim H, Abuaysheh S, Sia CL, Korzeniewski K, Chaudhuri A, Fernandez-Real JM \& Dandona P 2009 Increase in plasma endotoxin concentrations and the expression of Toll-like receptors and suppressor of cytokine signaling-3 in mononuclear cells after a high-fat, high-carbohydrate meal: implications for insulin resistance. Diabetes Care 32 2281-2287. (doi:10.2337/dc09-0979)

Ghanim H, Sia CL, Upadhyay M, Korzeniewski K, Viswanathan P, Abuaysheh S, Mohanty P \& Dandona P 2010 Orange juice neutralizes the proinflammatory effect of a high-fat, high-carbohydrate meal and prevents endotoxin increase and Toll-like receptor expression. American Journal of Clinical Nutrition 91 940-949. (doi:10.3945/ ajcn.2009.28584)

Giusti L, Gabriele M, Penno G, Garofolo M, Longo V, Del Prato S, Lucchesi D \& Pucci L 2017 A fermented whole grain prevents lipopolysaccharides-induced dysfunction in human endothelial progenitor cells. Oxidative Medicine and Cellular Longevity 2017 1026268.

Gomez de Agüero M, Ganal-Vonarburg SC, Fuhrer T, Rupp S, Uchimura Y, Li H, Steinert A, Heikenwalder M, Hapfelmeier S, Sauer U, et al. 2016 The maternal microbiota drives early postnatal innate immune development. Science 351 1296-1302. (doi:10.1126/science.aad2571)

Granowitz EV, Porat R, Mier JW, Orencole SF, Kaplanski G, Lynch EA, Ye K, Vannier E, Wolff SM \& Dinarello CA 1993 Intravenous endotoxin suppresses the cytokine response of peripheral blood mononuclear cells of healthy humans. Journal of Immunology 151 1637-1645.

Grönlund MM, Arvilommi H, Kero P, Lehtonen OP \& Isolauri E 2000 Importance of intestinal colonisation in the maturation of humoral immunity in early infancy: a prospective follow up study of healthy infants aged 0-6 months. Archives of Disease in Childhood 83 F186-F192. (doi:10.1136/fn.83.3.f186)

Heikkilä MP \& Saris PE 2003 Inhibition of Staphylococcus aureus by the commensal bacteria of human milk. Journal of Applied Microbiology 95 471-478. (doi:10.1046/j.1365-2672.2003.02002.x)

Hill CJ, Lynch DB, Murphy K, Ulaszewska M, Jeffery IB, O'Shea CA, Watkins C, Dempsey E, Mattivi F, Touhy K, et al. 2017 Evolution of gut microbiota composition from birth to 24 weeks in the INFANTMET Cohort. Microbiome 5 4. (doi:10.1186/s40168-0160213-y)

Hooper LV, Xu J, Falk PG, Midtvedt T \& Gordon JI 1999 A molecular sensor that allows a gut commensal to control its nutrient foundation in a competitive ecosystem. PNAS 96 9833-9838. (doi:10.1073/ pnas.96.17.9833)
Ip S, Chung M, Raman G, Trikalinos TA \& Lau J 2009 A summary of the Agency for Healthcare Research and Quality's evidence report on breastfeeding in developed countries. Breastfeeding Medicine 41 S17-S30. (doi:10.1089/bfm.2009.0050)

Jakobsson HE, Abrahamsson TR, Jenmalm MC, Harris K, Quince C, Jernberg C, Björkstén B, Engstrand L \& Andersson AF 2014 Decreased gut microbiota diversity, delayed Bacteroidetes colonisation and reduced Th1 responses in infants delivered by caesarean section. Gut 63 559-566. (doi:10.1136/gutjnl-2012-303249)

Jantscher-Krenn E, Lauwaet T, Bliss LA, Reed SL, Gillin FD \& Bode L 2012 Human milk oligosaccharides reduce Entamoeba histolytica attachment and cytotoxicity in vitro. British Journal of Nutrition $\mathbf{1 0 8}$ 1839-1846. (doi:10.1017/S0007114511007392)

Jimenez E, Marin ML, Martin R, Odriozola JM, Olivares M, Xaus J, Fernandez L \& Rodriguez JM 2008 Is meconium from healthy newborns actually sterile? Research in Microbiology 159 187-193. (doi:10.1016/j.resmic.2007.12.007)

Jones AD, Zhao G, Jiang YP, Zhou M, Xu G, Kaciroti N, Zhang Z \& Lozoff B 2016 Maternal obesity during pregnancy is negatively associated with maternal and neonatal iron status. European Journal of Clinical Nutrition 70 918-924. (doi:10.1038/ejcn.2015.229)

Kamada N, Chen GY, Inohara N \& Núñez G 2013 Control of pathogens and pathobionts by the gut microbiota. Nature Immunology 14 685-690. (doi:10.1038/ni.2608)

Kelly B \& O’Neill LA 2015 Metabolic reprogramming in macrophages and dendritic cells in innate immunity. Cell Research 25 771-784. (doi:10.1038/cr.2015.68)

Koch MA, Reiner GL, Lugo KA, Kreuk LS, Stanbery AG, Ansaldo E, Seher TD, Ludington WB \& Barton GM 2016 Maternal IgG and IgA antibodies dampen mucosal $\mathrm{T}$ helper cell responses in early life. Cell 165 827-841. (doi:10.1016/j.cell.2016.04.055)

Koren O, Goodrich JK, Cullender TC, Spor A, Laitinen K, Bäckhed HK, Gonzalez A, Werner JJ, Angenent LT, Knight R, et al. 2012 Host remodeling of the gut microbiome and metabolic changes during pregnancy. Cell 150 470-480. (doi:10.1016/j.cell.2012.07.008)

Kramer CD \& Genco CA 2017 Microbiota, immune subversion, and chronic inflammation. Frontiers in Immunology 8255.

Lassenius MI, Pietiläinen KH, Kaartinen K, Pussinen PJ, Syrjanen J, Forsblom C, Pörsti I, Rissanen A, Kaprio J, Mustonen J, et al. 2011 Bacterial endotoxin activity in human serum is associated with dyslipidemia, insulin resistance, obesity, and chronic inflammation. Diabetes Care 34 1809-1815. (doi:10.2337/dc10-2197)

Latuga MS, Stuebe A \& Seed PC 2014 A review of the source and function of microbiota in breast milk. Seminars in Reproductive Medicine 32 68-73. (doi:10.1055/s-0033-1361824)

Laugerette F, Vors C, Géloën A, Chauvin MA, Soulage C, LambertPorcheron S, Peretti N, Alligier M, Burcelin R, Laville M, et al. 2011 Emulsified lipids increase endotoxemia: possible role in early postprandial low-grade inflammation. Journal of Nutritional Biochemistry 22 53-59. (doi:10.1016/j.jnutbio.2009.11.011)

Le Roy T, Llopis M, Lepage P, Bruneau A, Rabot S, Bevilacqua C, Martin P, Philippe C, Walker F, Bado A, et al. 2013 Intestinal microbiota determines development of non-alcoholic fatty liver disease in mice. Gut 62 1787-1794. (doi:10.1136/gutjnl-2012-303816)

Leatham-Jensen MP, Frimodt-Møller J, Adediran J, Mokszycki ME, Banner ME, Caughron JE, Krogfelt KA, Conway T \& Cohen PS 2012 The streptomycin-treated mouse intestine selects Escherichia coli envZ missense mutants that interact with dense and diverse intestinal microbiota. Infection and Immunity 80 1716-1727. (doi:10.1128/ IAI.06193-11)

Lemas DJ, Young BE, Baker PR II, Tomczik AC, Soderborg TK, Hernandez TL, de la Houssaye BA, Robertson CE, Rudolph MC, Ir D, et al. 2016 Alterations in human milk leptin and insulin are associated with early changes in the infant intestinal microbiome. American Journal of Clinical Nutrition 103 1291-1300. (doi:10.3945/ajcn.115.126375) http://joe.endocrinology-journals.org

DOI: $10.1530 / \mathrm{JOE}-17-0303$
๑ 2017 Society for Endocrinology Printed in Great Britain 
Luo Y, Chen GL, Hannemann N, Ipseiz N, Krönke G, Bäuerle T, Munos L, Wirtz S, Schett G \& Bozec A 2015 Microbiota from obese mice regulate hematopoietic stem cell differentiation by altering the bone niche. Cell Metabolism 22 886-894. (doi:10.1016/j.cmet.2015.08.020)

Ma J, Prince AL, Bader D, Hu M, Ganu R, Baquero K, Blundell P, Harris RA, Frias AE, Grove KL, et al. 2014 High-fat maternal diet during pregnancy persistently alters the offspring microbiome in a primate model. Nature Communications 53889.

Martín R, Heilig HG, Zoetendal EG, Jimenez E, Fernandez L, Smidt H \& Rodriguez JM 2007 Cultivation-independent assessment of the bacterial diversity of breast milk among healthy women. Research in Microbiology 158 31-37. (doi:10.1016/j.resmic.2006.11.004)

McCurdy CE, Bishop JM, Williams SM, Grayson BE, Smith MS, Friedman JE \& Grove KL 2009 Maternal high-fat diet triggers lipotoxicity in the fetal livers of nonhuman primates. Journal of Clinical Investigation 119 323-335.

Medzhitov R 2001 Toll-like receptors and innate immunity. Nature Reviews Immunology 1 135-145. (doi:10.1038/35100529)

Mirpuri J, Raetz M, Sturge CR, Wilhelm CL, Benson A, Savani RC, Hooper LV \& Yarovinsky F 2014 Proteobacteria-specific IgA regulates maturation of the intestinal microbiota. Gut Microbes 5 28-39. (doi:10.4161/gmic.26489)

Miskinyte M \& Gordo I 2013 Increased survival of antibiotic-resistant Escherichia coli inside macrophages. Antimicrobial Agents and Chemotherapy 57 189-195. (doi:10.1128/AAC.01632-12)

Moya A \& Ferrer M 2016 Functional redundancy-induced stability of gut microbiota subjected to disturbance. Trends in Microbiology 24 402-413. (doi:10.1016/j.tim.2016.02.002)

Mueller NT, Shin H, Pizoni A, Werlang IC, Matte U, Goldani MZ, Goldan HA \& Dominguez-Bello MG 2016 Birth mode-dependent association between pre-pregnancy maternal weight status and the neonatal intestinal microbiome. Scientific Reports 6 23133. (doi:10.1038/ srep23133)

Myles IA, Fontecilla NM, Janelsins BM, Vithayathil PJ, Segre JA \& Datta SK 2013 Parental dietary fat intake alters offspring microbiome and immunity. Journal of Immunology 191 3200-3209. (doi:10.4049/ jimmunol.1301057)

Nemeth E, Rivera S, Gabayan V, Keller C, Taudorf S, Pedersen BK \& Ganz T 2004a IL- 6 mediates hypoferremia of inflammation by inducing the synthesis of the iron regulatory hormone hepcidin. Journal of Clinical Investigation 113 1271-1276. (doi:10.1172/JCI200420945)

Nemeth E, Tuttle MS, Powelson J, Vaughn MB, Donovan A, Ward DM, Ganz T \& Kaplan J 2004b Hepcidin regulates cellular iron efflux by binding to ferroportin and inducing its internalization. Science 306 2090-2093. (doi:10.1126/science.1104742)

Neu J 2015 Preterm infant nutrition, gut bacteria, and necrotizing enterocolitis. Current Opinion in Clinical Nutrition and Metabolic Care 18 285-288. (doi:10.1097/MCO.0000000000000169)

Neu J 2016 Intestinal microbiota studies in preterm infants. Journal of Pediatric Gastroenterology and Nutrition 62 193-194. (doi:10.1097/ MPG.0000000000001068)

Newton KP, Feldman HS, Chambers CD, Wilson L, Behling C, Clark JM, Molleston JP, Chalasani N, Sanyal AJ, Fishbein MH, et al. 2017 Low and high birth weights are risk factors for nonalcoholic fatty liver disease in children. Journal of Pediatrics (doi:10.1016/j. jpeds.2017.1003.1007)

Ng RL, Scott NM, Strickland DH, Gorman S, Grimbaldeston MA, Norval M, Waithman J \& Hart PH 2013 Altered immunity and dendritic cell activity in the periphery of mice after long-term engraftment with bone marrow from ultraviolet-irradiated mice. Journal of Immunology 190 5471-5484. (doi:10.4049/jimmunol.1202786)

Nicklas JM \& Barbour LA 2015 Optimizing weight for maternal and infant health - tenable, or too late? Expert Review of Endocrinology and Metabolism 10 227-242. (doi:10.1586/17446651.2014.991102)

Ninonuevo MR, Park Y, Yin H, Zhang J, Ward RE, Clowers BH, German JB, Freeman SL, Killeen K, Grimm R, et al. 2006 A strategy for annotating the human milk glycome. Journal of Agricultural and Food Chemistry $\mathbf{5 4}$ 7471-7480. (doi:10.1021/jf0615810)

Ogden CL, Carroll MD, Kit BK \& Flegal KM 2012 Prevalence of obesity and trends in body mass index among US children and adolescents, 1999-2010. JAMA 307 483-490. (doi:10.1001/jama.2012.40)

Ogra PL \& Welliver RC Sr 2008 Effects of early environment on mucosal immunologic homeostasis, subsequent immune responses and disease outcome. Nestlé Nutrition Workshop Series Paediatric Programme 61 145-181. (doi:10.1159/000113492)

Palmer C, Bik EM, DiGiulio DB, Relman DA \& Brown PO 2007 Development of the human infant intestinal microbiota. PLoS Biology 5 e177. (doi:10.1371/journal.pbio.0050177)

Paul HA, Bomhof MR, Vogel HJ \& Reimer RA 2016 Diet-induced changes in maternal gut microbiota and metabolomic profiles influence programming of offspring obesity risk in rats. Scientific Reports 6 20683. (doi:10.1038/srep20683)

Penders J, Thijs C, Vink C, Stelma FF, Snijders B, Kummeling I, van den Brandt PA \& Stobberingh EE 2006 Factors influencing the composition of the intestinal microbiota in early infancy. Pediatrics 118 511-521. (doi:10.1542/peds.2005-2824)

Perez-Muñoz ME, Arrieta MC, Ramer-Tait AE \& Walter J 2017 A critical assessment of the 'sterile womb' and 'in utero colonization' hypotheses: implications for research on the pioneer infant microbiome. Microbiome 548.

Ridaura VK, Faith JJ, Rey FE, Cheng J, Duncan AE, Kau AL, Griffin NW, Lombard V, Henrissat B, Bain JR, et al. 2013 Gut microbiota from twins discordant for obesity modulate metabolism in mice. Science 341 1241214. (doi:10.1126/science.1241214)

Rodríguez JM 2014 The origin of human milk bacteria: is there a bacterial entero-mammary pathway during late pregnancy and lactation? Advances in Nutrition 5 779-784. (doi:10.3945/an.114.007229)

Ruiz AG, Casafont F, Crespo J, Cayón A, Mayorga M, Estebanez A, Fernadez-Escalante JC \& Pons-Romero F 2007 Lipopolysaccharidebinding protein plasma levels and liver TNF-alpha gene expression in obese patients: evidence for the potential role of endotoxin in the pathogenesis of non-alcoholic steatohepatitis. Obesity Surgery 17 1374-1380. (doi:10.1007/s11695-007-9243-7)

Santacruz A, Collado MC, García-Valdés L, Segura MT, Martín-Lagos JA, Anjos T, Martí-Romero M, Lopez RM, Florido J, Campoy C, et al. 2010 Gut microbiota composition is associated with body weight, weight gain and biochemical parameters in pregnant women. British Journal of Nutrition 104 83-92. (doi:10.1017/S0007114510000176)

Singer K, DelProposto J, Morris DL, Zamarron B, Mergian T, Maley N, Cho KW, Geletka L, Subbaiah P, Muir L, et al. 2014 Diet-induced obesity promotes myelopoiesis in hematopoietic stem cells. Molecular Metabolism 3 664-675. (doi:10.1016/j.molmet.2014.06.005)

Slocum C, Coats SR, Hua N, Kramer C, Papadopoulos G, Weinberg EO, Gudino CV, Hamilton JA, Darveau RP \& Genco CA 2014 Distinct lipid a moieties contribute to pathogen-induced site-specific vascular inflammation. PLoS Pathogens 10 e1004215. (doi:10.1371/journal. ppat.1004215)

Spencer MD, Hamp TJ, Reid RW, Fischer LM, Zeisel SH \& Fodor AA 2011 Association between composition of the human gastrointestinal microbiome and development of fatty liver with choline deficiency. Gastroenterology 140 976-986. (doi:10.1053/j.gastro.2010.11.049)

Sze MA \& Schloss PD 2016 Looking for a signal in the noise: revisiting obesity and the microbiome. mBio 7 e01018-16. (doi:10.1128/ mbio.01018-16)

Tang M, Frank DN, Sherlock L, Ir D, Robertson CE \& Krebs NF 2016 Effect of vitamin E with therapeutic iron supplementation on iron repletion and gut microbiome in US iron deficient infants and toddlers. Journal of Pediatric Gastroenterology and Nutrition 63 379-385. (doi:10.1097/ MPG.0000000000001154)

Thevaranjan N, Puchta A, Schulz C, Naidoo A, Szamosi JC, Verschoor CP, Loukov D, Schenck LP, Jury J, Foley KP, et al. 2017 Age-associated microbial dysbiosis promotes intestinal permeability, systemic 
inflammation, and macrophage dysfunction. Cell Host and Microbe 21 455-466.e454. (doi:10.1016/j.chom.2017.03.002)

Thorn SR, Baquero KC, Newsom SA, El Kasmi KC, Bergman BC, Shulman GI, Grove KL \& Friedman JE 2014 Early life exposure to maternal insulin resistance has persistent effects on hepatic NAFLD in juvenile nonhuman primates. Diabetes 63 2702-2713. (doi:10.2337/ db14-0276)

Turnbaugh PJ, Ley RE, Mahowald MA, Magrini V, Mardis ER \& Gordon JI 2006 An obesity-associated gut microbiome with increased capacity for energy harvest. Nature $\mathbf{4 4 4}$ 1027-1031. (doi:10.1038/nature05414)

Vatanen T, Kostic AD, d'Hennezel E, Siljand er H, Franzosa EA, Yassour M, Kolde R, Vlamakis H, Arthur TD, Hämäläinen AM, et al. 2016 Variation in microbiome LPS immunogenicity contributes to autoimmunity in humans. Cell 165 842-853. (doi:10.1016/ j.cell.2016.04.007)
Voreades N, Kozil A \& Weir TL 2014 Diet and the development of the human intestinal microbiome. Frontiers in Microbiology 5 1-9.

Weng M \& Walker WA 2013 The role of gut microbiota in programming the immune phenotype. Journal of Developmental Origins of Health and Disease 4 203-214. (doi:10.1017/S2040174412000712)

Wesolowski SR, El Kasmi KC, Jonscher KR \& Friedman JE 2017 Developmental origins of NAFLD: a womb with a clue. Nature Reviews: Gastroenterology and Hepatology 14 81-96. (doi:10.1038/nrgastro.2016.160)

Whitfield C \& Trent MS 2014 Biosynthesis and export of bacterial lipopolysaccharides. Annual Review of Biochemistry 83 99-128. (doi:10.1146/annurev-biochem-060713-035600)

Zeng MY, Cisalpino D, Varadarajan S, Hellman J, Warren HS, Cascalho M, Inohara N \& Núñez G 2016 Gut microbiota-induced immunoglobulin $\mathrm{G}$ controls systemic infection by symbiotic bacteria and pathogens. Immunity 44 647-658. (doi:10.1016/j.immuni.2016.02.006)

Received in final form 7 July 2017

Accepted 20 July 2017
Published by Bioscientifica Ltd. 